\title{
Efficacy and Safety of Once-Daily Vibegron for Treatment of Overactive Bladder in Patients Aged $\geq 65$ and $\geq 75$ Years: Subpopulation Analysis from the EMPOWUR Randomized, International, Phase III Study
}

\author{
Susann Varano ${ }^{1} \cdot$ David Staskin $^{2} \cdot$ Jeffrey Frankel $^{3} \cdot$ Denise Shortino $^{4} \cdot$ Rachael Jankowich $^{5} \cdot$ Paul N. Mudd Jr $^{5}$
}

Accepted: 28 November 2020 / Published online: 20 January 2021

(c) The Author(s) 2021

\begin{abstract}
Background Overactive bladder $(\mathrm{OAB})$ is common among older adults. The efficacy and safety of vibegron for the treatment of OAB were demonstrated in the international, phase III EMPOWUR trial. This subpopulation analysis from EMPOWUR assessed the efficacy and safety of vibegron in patients aged $\geq 65$ and $\geq 75$ years.

Methods In EMPOWUR, patients with OAB were randomly assigned 5:5:4 to receive once-daily vibegron $75 \mathrm{mg}$, placebo, or tolterodine $4 \mathrm{mg}$ extended release, respectively, once daily for 12 weeks. Coprimary efficacy endpoints were change from baseline at week 12 in average daily number of micturitions and urge urinary incontinence (UUI) episodes; a key secondary efficacy endpoint was change from baseline at week 12 in average daily number of urgency episodes. Safety was assessed through adverse events (AEs). Efficacy analyses compared vibegron with placebo; no efficacy comparisons were made between vibegron and tolterodine.

Results Of the 1463 patients with evaluable efficacy data, 628 patients were aged $\geq 65$ years, and 179 were aged $\geq 75$ years. After 12 weeks, patients treated with once-daily vibegron $75 \mathrm{mg}$ in both age subgroups showed significant improvements from baseline versus placebo in all three symptoms of OAB: daily micturitions ( $\geq 65$ years, $P<0.0001$; $\geq 75$ years, $P<0.05$ ), UUI episodes ( $\geq 65$ years, $P<0.001 ; \geq 75$ years, $P<0.0001$ ), and urgency episodes ( $\geq 65$ years, $P<0.01 ; \geq 75$ years, $P<0.01$ ). Significant reductions from baseline versus placebo in daily micturitions, UUI episodes, and urgency episodes were observed beginning at week 2 for patients aged $\geq 65$ years treated with vibegron. In patients aged $\geq 65$ years, $50.0 \%$ of those receiving vibegron versus $29.8 \%$ receiving placebo experienced a $\geq 75 \%$ reduction in UUI episodes at week $12(P<0.0001)$. Rates of cardiovascular-associated AEs were low for patients receiving vibegron ( $<2 \%$ of patients in either age subgroup) and similar to rates in patients receiving placebo. In patients aged $\geq 65$ years, hypertension was reported by $1.2 \%, 3.1 \%$, and $2.9 \%$ of patients receiving vibegron, placebo, and tolterodine, respectively; in patients aged $\geq 75$ years, hypertension was reported by $1.3 \%, 3.3 \%$, and $2.1 \%$, respectively.

Conclusions In this subpopulation analysis of patients with OAB aged $\geq 65$ and $\geq 75$ years from the EMPOWUR study, once-daily vibegron $75 \mathrm{mg}$ showed rapid onset and robust efficacy versus placebo and was generally safe and well tolerated, consistent with results from the overall population.
\end{abstract}

Trial Registration ClinicalTrials.gov identifier NCT03492281; registered April 10, 2018.

Susann Varano

varanos2@yahoo.com

1 Geriatric Medicine, Clinical Research Consulting, 2080 Bridgeport Avenue, Suite D, Milford, CT 06460, USA

2 Department of Surgery, Division of Urology, Tufts University School of Medicine, Boston, MA, USA

3 Urology, Seattle Urology Research Center, Seattle, WA, USA

4 Biostatistics, Urovant Sciences, Irvine, CA, USA

5 Clinical Development, Urovant Sciences, Irvine, CA, USA

\section{Introduction}

Overactive bladder $(\mathrm{OAB})$ is prevalent in the general population, and prevalence increases with age [1-4]. More than half of women aged 40-45 years report OAB symptoms (36.6\% "sometimes" and $25.8 \%$ "often"), and more than $85 \%$ of women aged $71-75$ years report OAB symptoms (48.7\% "sometimes" and $39.2 \%$ "often") [3]. In addition, the percentage of men seeking treatment for OAB is significantly correlated with older age [5]. Older patients receiving 


\section{Key Points}

In a subpopulation analysis of the phase III, 12-week EMPOWUR trial of patients with overactive bladder, patients receiving vibegron aged $\geq 65$ and $\geq 75$ years showed significant improvement from baseline in average daily micturitions and in average daily number of urge urinary incontinence and daily urgency episodes, similar to results of the overall population.

Rates of adverse events with vibegron were generally comparable to those with placebo within each age group and to those in the overall study population.

In patients with overactive bladder aged $\geq 65$ and $\geq 75$ years, treatment with vibegron was generally safe and well tolerated and demonstrated a safety profile consistent with that of the overall population.

treatment for $\mathrm{OAB}$ often receive a greater number of concomitant medications than those without OAB [6]; such polypharmacy can lead to an increased risk of clinically relevant drug-drug interactions (DDIs). Thus, polypharmacy must be carefully considered in the older adult population.

Symptoms of OAB, including urinary urgency with or without incontinence, can negatively affect patients' quality of life [5, 7-10]. Current guidelines for the treatment of OAB from the American Urological Association recommend the use of oral anticholinergics or $\beta_{3}$-adrenergic receptor agonists as either second-line treatment after behavioral therapy or as first-line therapy in combination with behavioral therapy $[11,12]$. However, anticholinergics are associated with bothersome side effects such as dry mouth [13] and an increased risk for dementia [14]. Guidelines from the American Geriatrics Society recommend limiting the use of anticholinergics in older patients because of increased risk of anticholinergic effects [15].

$\beta_{3}$-adrenergic receptor agonists infrequently cause dry mouth and have not been associated with drug-related cognitive side effects $[13,16]$. Vibegron is a novel, potent, highly selective $\beta_{3}$-adrenergic receptor agonist that does not inhibit cytochrome P450 (CYP) 2D6 [17]. The efficacy and safety of vibegron for relieving the symptoms of OAB were demonstrated in EMPOWUR, an international 12-week placebo- and active-controlled phase III trial [18]. Patients who received vibegron had significant improvement from baseline for both coprimary endpoints at week 2 compared with placebo, and these improvements were sustained through week 12 (micturition frequency, $P<0.001$; urge urinary incontinence [UUI] episode frequency, $P<0.0001)$. This subpopulation analysis from EMPOWUR assessed the efficacy and safety of vibegron in patients aged $\geq 65$ and $\geq 75$ years.

\section{Methods}

\subsection{Study Design and Participants}

EMPOWUR (NCT03492281) was a 12-week, double-blind, controlled study of vibegron that used both a placebo and an active control (tolterodine); detailed methods have been reported previously [18]. The study included a 2-week placebo run-in; participants were required to demonstrate $\geq 80 \%$ compliance with self-administration of study treatment. Adults were included if they had a history of OAB for at least 3 months before the screening visit and met prespecified criteria for wet or dry OAB (i.e., urinary urgency with or without urge incontinence, respectively). Criteria for wet $\mathrm{OAB}$ (i.e., urinary incontinence) specified that a 7-day diary showed an average of eight or more daily micturitions and one or more daily UUI episode. Criteria for dry OAB specified that a 7-day diary showed an average of eight or more daily micturitions, three or more daily urgency episodes, and fewer than one daily UUI episode. Up to $25 \%$ of the study population could have dry OAB. Enrollment of men was limited to $15 \%$ of the study population. Patients were excluded if they had a history of 24-h urine volume $>3000 \mathrm{~mL}$ in the past 6 months, lower urinary tract pathology (e.g., bladder outlet obstruction) that could account for OAB symptoms, history of stress urinary incontinence surgery within 6 months of screening, intradetrusor injection of botulinum toxin within 9 months of screening, or electrostimulation within 28 days of screening. Additional exclusion criteria were diabetes insipidus, uncontrolled hyperglycemia (fasting blood glucose $>150 \mathrm{mg} / \mathrm{dL}$ or $8.33 \mathrm{mmol} / \mathrm{L}$ and/or non-fasting blood glucose $>200 \mathrm{mg} / \mathrm{dL}$ or $11.1 \mathrm{mmol} / \mathrm{L}$ or, if in the opinion of the investigator, was uncontrolled), current history or evidence of stage $\geq 2$ pelvic organ prolapse or use of pessary for the treatment of pelvic organ prolapse, and history of neurodegenerative diseases (e.g., multiple sclerosis, Parkinson disease) that could affect the lower urinary tract or its nerve supply. Patients were randomly assigned 5:5:4 to receive vibegron $75 \mathrm{mg}$, placebo, or tolterodine $4 \mathrm{mg}$ extended release, respectively, once daily for 12 weeks.

\subsection{Assessments}

\subsubsection{Efficacy}

Data were collected from a 7-day event and 1-day volume diary completed by the patients at baseline and at weeks 2 , 4,8 , and 12 . The coprimary efficacy endpoints were change from baseline to week 12 in the frequency of micturition and frequency of UUI episodes per day (i.e., number of micturitions and UUI episodes over $24 \mathrm{~h}$ ). A key secondary efficacy measure was change from baseline to week 12 in average number of urgency episodes per day. 


\subsubsection{Safety}

Adverse events (AEs) and serious AEs were collected from the time of informed consent until the follow-up visit. Treatment-emergent AEs were defined as occurring during the period of time from the first dose through 28 days after the last dose of study medication. Hypertension was predefined as an $\mathrm{AE}$ of interest and defined as follows: for patients without baseline hypertension, an average of three systolic blood pressure (BP) readings $\geq 140 \mathrm{mmHg}$ and/or diastolic BP readings $\geq 90 \mathrm{mmHg}$ at two consecutive visits; for patients with baseline hypertension, an average of three readings showing increases from baseline of $\geq 20 \mathrm{mmHg}$ systolic BP or $\geq 10 \mathrm{mmHg}$ diastolic BP at two consecutive visits; for any patient, increased dosing or initiation of any medication to treat hypertension. Baseline hypertension was defined as systolic BP $\geq 140 \mathrm{mmHg}$ and diastolic $\mathrm{BP} \geq 90$ $\mathrm{mmHg}$.

\subsection{Statistical Analyses}

The subpopulation analysis assessed efficacy and safety in patients aged $\geq 65$ and $\geq 75$ years (a subset of the population aged $\geq 65$ years). The full analysis set, defined as all randomized patients who received at least one dose of doubleblind study treatment and had at least one evaluable change from baseline micturition frequency assessment, was used for all non-incontinence efficacy endpoints. The full analysis set for incontinence was defined as randomized patients who had wet $\mathrm{OAB}$ at study entry who received at least one dose of double-blind study treatment and had at least one evaluable change from baseline UUI measurement. A mixed model for repeated measures (MMRM) with restricted maximum likelihood estimation was used to evaluate changes from baseline for continuous efficacy endpoints. The models included data from weeks $2,4,8$, and 12 . Covariates for all patients and patients aged $\geq 65$ years included study visit, age group, sex, region, OAB type (full analysis set only), baseline, and interaction terms. The model used for patients aged $\geq 75$ years was a post hoc analysis and did not include sex or region because of the small sample size. Estimates of least squares (LS) means and standard errors (SEs) for each treatment group and the statistical significance levels based on tests of treatment difference (vibegron or tolterodine vs. placebo) were provided.

For patients aged $\geq 65$ years, post hoc responder analyses were performed to determine the proportion of patients with $\geq 50 \%$ reduction from baseline in the average number of daily urgency episodes and $\geq 75 \%$ or $100 \%$ reduction in average number of daily UUI episodes. The estimated differences in the proportion of responders (vibegron or tolterodine vs. placebo) were analyzed using the Cochran-Mantel-Haenszel risk difference estimate and were stratified by
OAB type (full analysis set only) and sex. Missing data were imputed using multiple imputations.

Safety data were summarized for all patients who received at least one dose of double-blinded study treatment (safety set).

\subsection{Ethical Conduct}

The EMPOWUR study was conducted in compliance with International Conference on Harmonisation of Technical Requirements for Registration of Pharmaceuticals for Human Use Good Clinical Practice. Each investigator obtained study approval from an institutional review board, research ethics board, or independent ethics committee before study initiation. All patients provided written informed consent before undergoing any study procedures.

\section{Results}

\subsection{Patients}

The study was conducted between March 2018 and February 2019 at 199 study sites in the USA, Canada, Poland, Hungary, Latvia, and Lithuania. In the overall study, 1518 patients were enrolled ( $\geq 65$ years, $n=647 ; \geq 75$ years, $n=183$; Fig. 1), and 1515 patients received at least one dose of study treatment. Of these, 1463 patients were included in the full analysis set. Overall mean \pm standard deviation age of the EMPOWUR study was $60.2 \pm 13.3$ years. In the subpopulation analysis, the full analysis set comprised 628 patients ( $42.9 \%$ of the overall population) aged $\geq 65$ years (Fig. 1a; Table 1) and 179 patients (12.2\% of the overall population) aged $\geq 75$ years (Fig. 1 b; Table 1 ).

\subsection{Efficacy Endpoints}

Treatment with vibegron was associated with significant reductions in LS mean daily number of micturitions versus placebo at week 12 for patients aged $\geq 65$ years $(P<0.0001$; Fig. 2a) and patients aged $\geq 75$ years $(P<0.05$ : Fig. $2 b)$, consistent with the overall population $(P<0.001)$. Patients treated with vibegron in both age subgroups also had significant reductions in LS mean daily number of UUI episodes versus placebo at week 12 ( $\geq 65$ years, $P<0.001 ; \geq 75$ years, $P<0.0001$; Fig. 3), consistent with the overall population $(P<0.0001)$. LS mean change from baseline in daily number of UUI episodes at week 12 was the same as or numerically greater for vibegron than for tolterodine across age groups. At week 12, LS mean change from baseline in daily urgency episodes was significantly reduced for vibegron versus placebo in both age subgroups $(P<0.01$, each; Fig. 4$)$ and in the overall population $(P<0.01)$. 


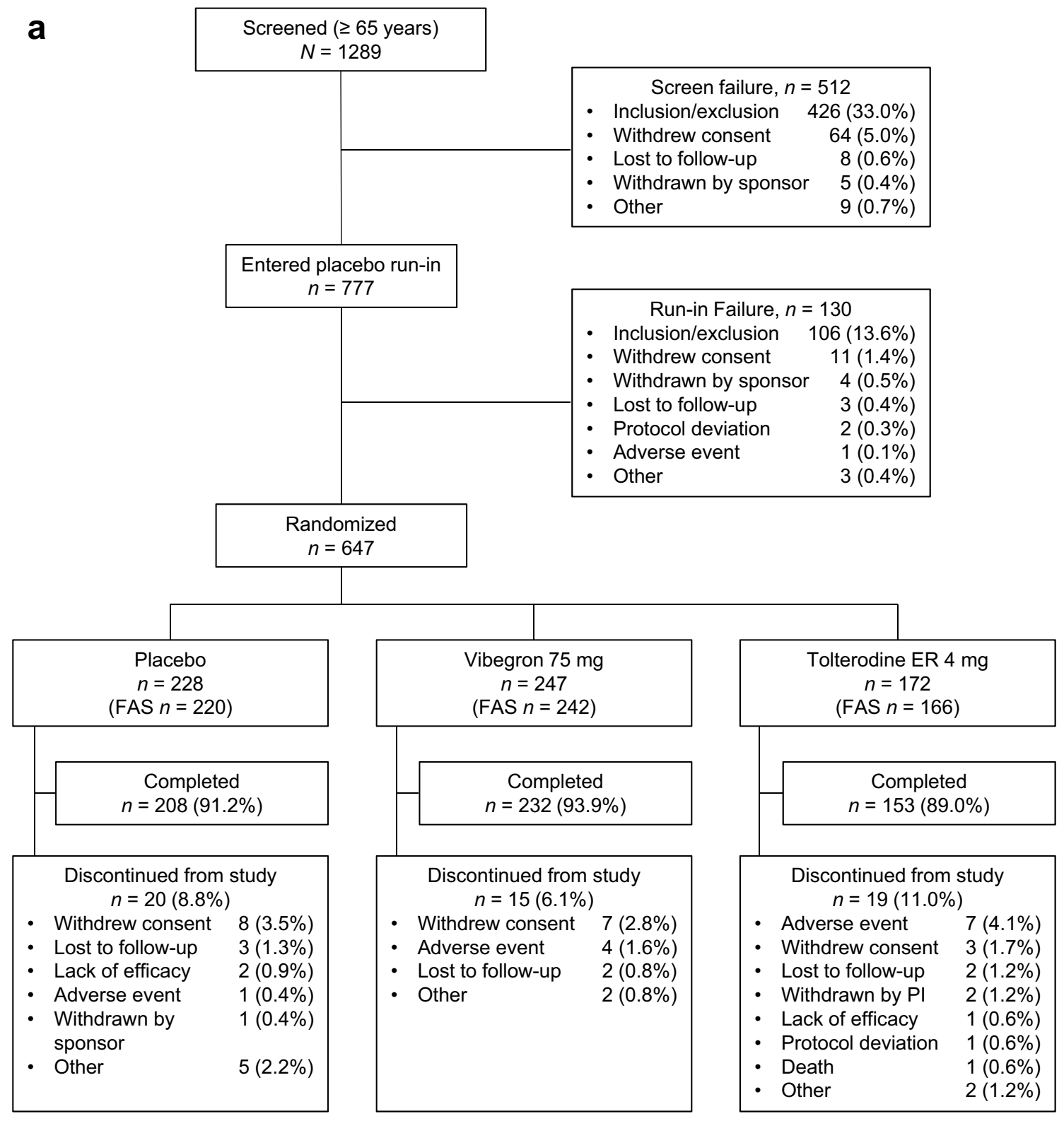

Fig. 1 Patient disposition for patients (a) $\geq 65$ years and (b) $\geq 75$ years. ER extended release, FAS full analysis set, PI principal investigator

Across all efficacy measures, results observed in the population aged $\geq 65$ years were similar to results from the overall population. For patients aged $\geq 65$ years, significant reductions in micturition frequency (Fig. 2a), UUI episodes (Fig. 3a), and daily urgency episodes (Fig. 4a) with vibegron compared with placebo emerged as early as week 2 ; in the overall population [18], significant reductions from baseline were observed at every time point versus placebo for both micturition frequency $(P<0.001)$ and urgency episode frequency $(P<0.01)$. Across age groups, LS mean change from baseline in average daily number of micturitions was numerically greater for vibegron than tolterodine at all time points (Fig. 2).
In patients aged $\geq 65$ years, $50.0 \%$ receiving vibegron and $29.8 \%$ receiving placebo had $\mathrm{a} \geq 75 \%$ reduction in UUI episodes $(P<0.0001)$ from baseline to week $12 ; 38.7 \%$ and $28.8 \%$, respectively, had a $\geq 50 \%$ reduction in urgency episodes at week $12(P<0.05$; Table 2$)$.

\subsection{Safety}

The incidence of AEs with vibegron was generally comparable to that with tolterodine within each age group and to the overall study population (Table 3 ). AEs occurring in $\geq 2 \%$ of vibegron-treated patients aged $\geq 65$ years and more frequently than placebo were headache, dry mouth, 


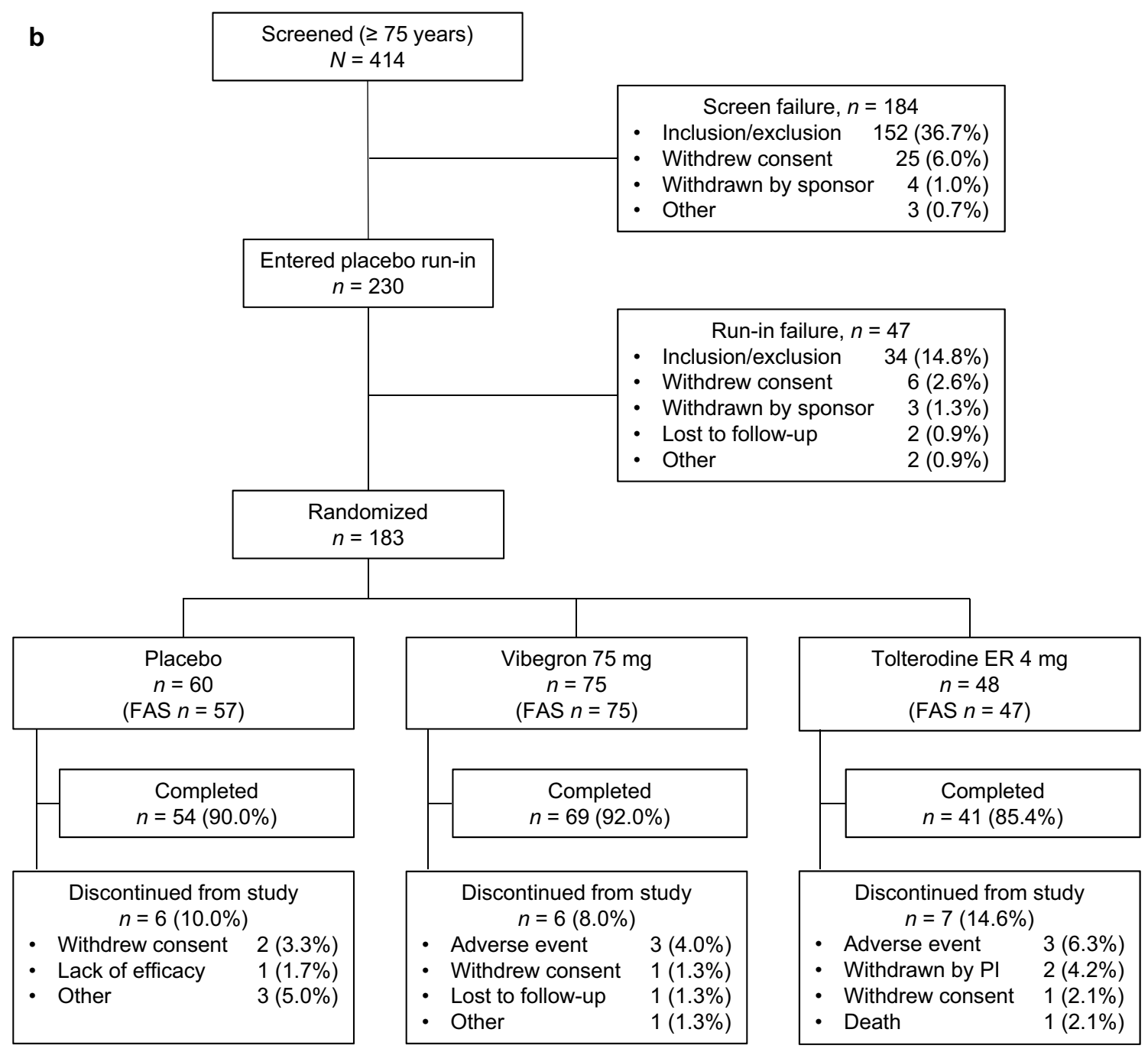

Fig. 1 (continued)

upper respiratory tract infections, nasopharyngitis, diarrhea, and nausea. AEs occurring in $\geq 2 \%$ of patients aged $\geq 75$ years treated with vibegron and more frequently than placebo were urinary tract infection, diarrhea, upper respiratory tract infection, dyspnea, urinary retention, rash, somnolence, and flatulence. Dry mouth was more common in tolterodine-treated patients (occurring in $\geq 4 \%$ of patients across all age groups) than in vibegron-treated patients.

Rates of hypertension for vibegron ( $\geq 65$ years, $1.2 \%$; $\geq 75$ years, $1.3 \%$; overall, $1.7 \%$ ) were lower than or similar to the rates reported for both placebo ( $\geq 65$ years, $3.1 \%$; $\geq 75$ years, $3.3 \%$; overall, $1.7 \%$ ) and tolterodine ( $\geq 65$ years,
$2.9 \%$; $\geq 75$ years, $2.1 \%$; overall, $2.6 \%$ ). The incidence of cardiovascular-associated AEs was infrequent in vibegrontreated patients and similar to that in patients receiving placebo (Table 3).

\section{Discussion}

Treatment with vibegron $75 \mathrm{mg}$ once daily for 12 weeks was efficacious in the overall OAB population, including in patients aged $\geq 65$ and $\geq 75$ years. Statistically significant benefits with vibegron versus placebo were seen in patients 
Table 1 Key patient baseline demographics and clinical characteristics (full analysis set ${ }^{\mathrm{a}}$ )

\begin{tabular}{llll}
\hline Characteristic & Placebo $(N=520)$ & Vibegron $(N=526)$ & Tolterodine $(N=417)$ \\
\hline Age, years & $59.9 \pm 13.3$ & $60.8 \pm 13.3$ & $59.8 \pm 13.2$ \\
Age subgroup, years & & & \\
Age $\geq 65$ years & $220(42.3)$ & $242(46.0)$ & $166(39.8)$ \\
Age $\geq 75$ years & $57(11.0)$ & $75(14.3)$ & $47(11.3)$ \\
Women & $445(85.6)$ & $449(85.4)$ & $352(84.4)$ \\
Age $\geq 65$ years $^{\mathrm{b}}$ & $178(80.9)$ & $204(84.3)$ & $132(79.5)$ \\
Age $\geq 75$ years $^{\mathrm{c}}$ & $43(75.4)$ & $59(78.7)$ & $35(74.5)$ \\
Men & $75(14.4)$ & $77(14.6)$ & $65(15.6)$ \\
Age $\geq 65$ years $^{\mathrm{b}}$ & $42(19.1)$ & $38(15.7)$ & $34(20.5)$ \\
Age $\geq 75$ years $^{\mathrm{c}}$ & $14(24.6)$ & $16(21.3)$ & $12(25.5)$ \\
OAB wet & $405(77.9)$ & $403(76.6)$ & $319(76.5)$ \\
Age $\geq 65$ years $^{\mathrm{b}}$ & $168(76.4)$ & $192(79.3)$ & $128(77.1)$ \\
Age $\geq 75$ years $^{\mathrm{c}}$ & $44(77.2)$ & $59(78.7)$ & $36(76.6)$ \\
OAB dry & $115(22.1)$ & $123(23.4)$ & $98(23.5)$ \\
Age $\geq 65$ years $^{\mathrm{b}}$ & $52(23.6)$ & $50(20.7)$ & $38(22.9)$ \\
Age $\geq 75$ years $^{\mathrm{c}}$ & $13(22.8)$ & $16(21.3)$ & $11(23.4)$ \\
\hline
\end{tabular}

Data are presented as mean \pm standard deviation or $n(\%)$ unless otherwise indicated

$O A B$ overactive bladder

${ }^{a}$ Patients from the safety set $(N=1515)$ were excluded from the full analysis set for one or more reasons (i.e., they did not have a baseline or at least one post-baseline micturition assessment or they did not receive double-blind study medication)

${ }^{b}$ Percentage calculated from the subset of patients aged $\geq 65$ years in each treatment group

${ }^{c}$ Percentage calculated from the subset of patients aged $\geq 75$ years in each treatment group
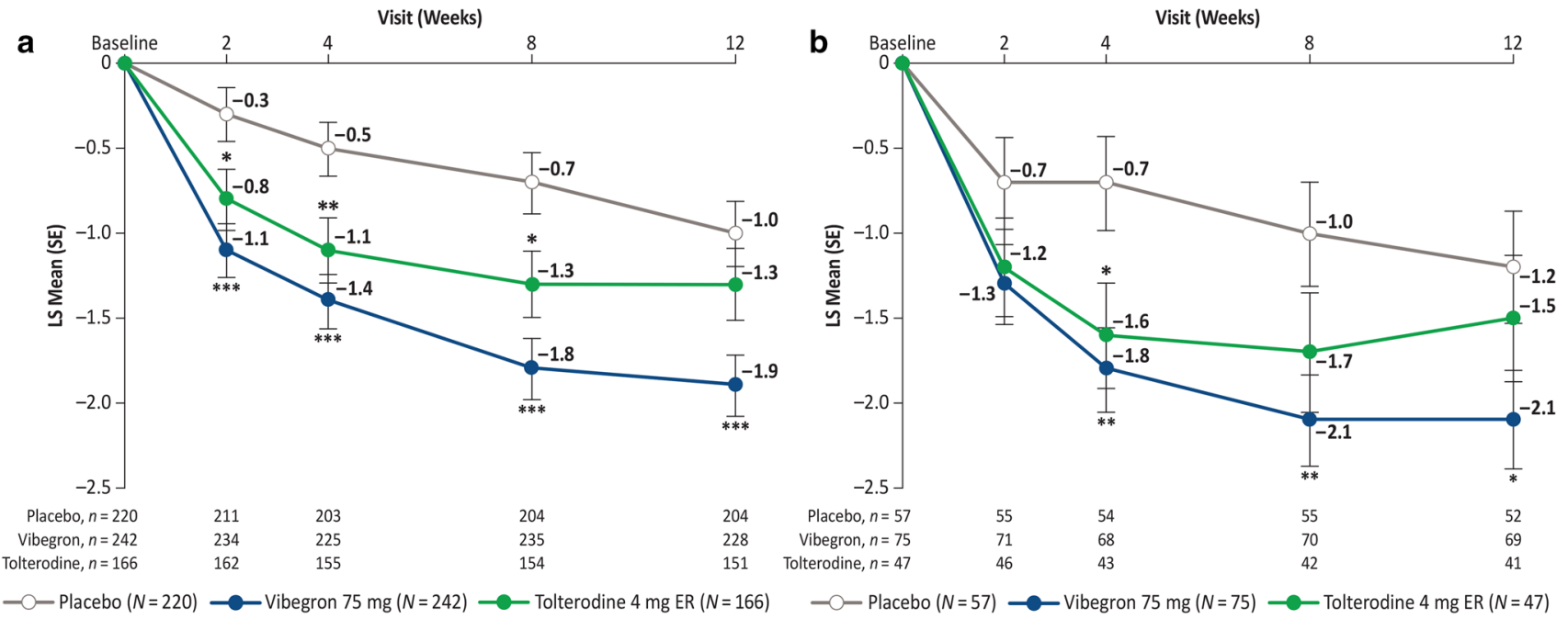

$\longrightarrow$ Placebo $(N=220) \longrightarrow$ Vibegron $75 \mathrm{mg}(N=242) \longrightarrow$ Tolterodine $4 \mathrm{mg}$ ER $(N=166)$

$-O$ Placebo $(N=57)$

-Vibegron $75 \mathrm{mg}(N=75) \longrightarrow$ Tolterodine $4 \mathrm{mg} \operatorname{ER}(N=47)$

Fig. 2 Change from baseline in average daily number of micturitions for patients aged (a) $\geq 65$ years and (b) $\geq 75$ years in the full analysis set. $E R$ extended release, $L S$ least squares, $S E$ standard error. ${ }^{*} P<0.05, * * P<0.01, * * * P<0.001$ vs. placebo using mixed model for repeated measures 

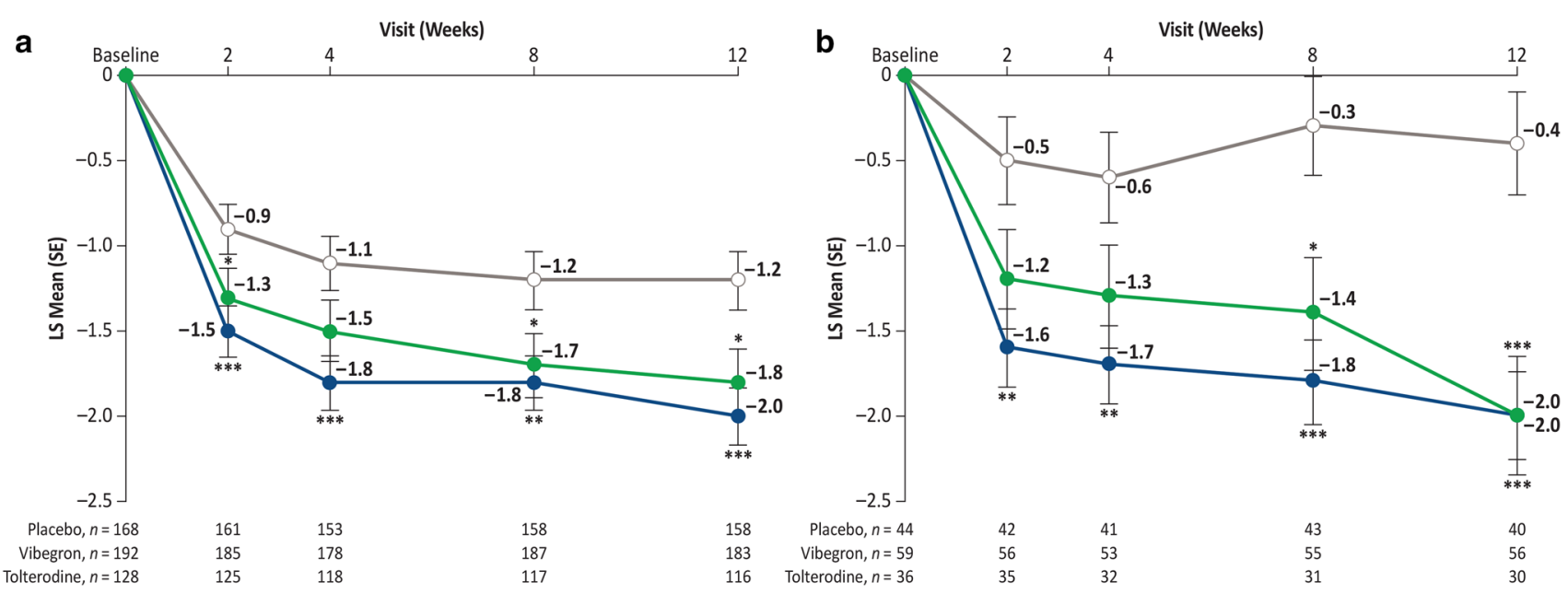

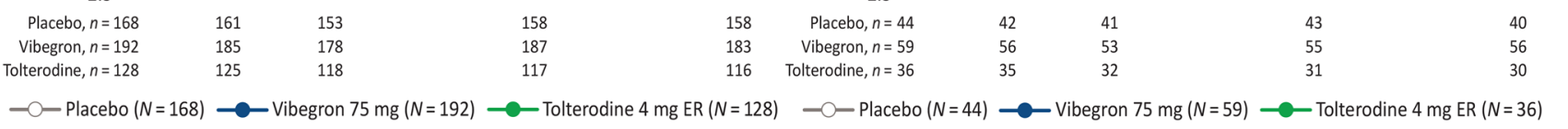

Fig. 3 Change from baseline in average daily number of urge urinary incontinence episodes for patients aged $\mathbf{a} \geq 65$ years and $\mathbf{b} \geq 75$ years in the full analysis set for incontinence. $E R$ extended release, $L S$ least squares, $S E$ standard error. $* P<0.05$, $* * P<0.01$, ***P $P<0.001$ vs. placebo using mixed model for repeated measures

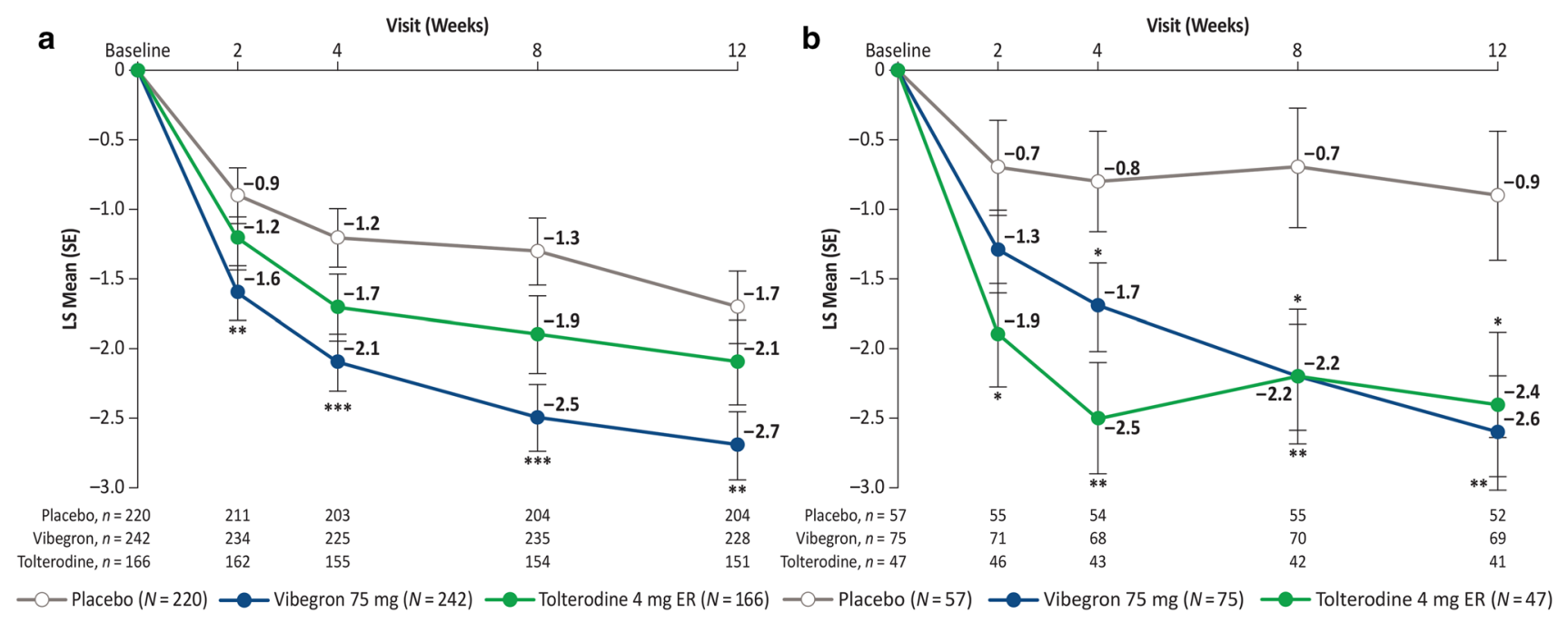

Fig. 4 Change from baseline in average daily urgency episodes for patients aged $\mathbf{a} \geq 65$ years and $\mathbf{b} \geq 75$ years in the full analysis set. $L S$ least squares, $S E$ standard error. $* P<0.05, * * P<0.01,{ }^{*} * P<0.001$ vs. placebo using mixed model for repeated measures

Table 2 Responder analysis in patients aged $\geq 65$ years $^{\mathrm{a}}$ (full analysis set)

\begin{tabular}{llll}
\hline Analysis, $\mathrm{n}(\%)$ & Placebo $(N=220)$ & Vibegron $(N=242)$ & Tolterodine $(N=166)$ \\
\hline$\geq 75 \%$ reduction in UUI episodes & $50(29.8)$ & $96(50.0)^{* *}$ & $55(43.0)^{*}$ \\
$50 \%$ reduction in urgency episodes & $63(28.8)$ & $94(38.7)^{*}$ & $49(29.5)$ \\
\hline
\end{tabular}

UUI urge urinary incontinence

${ }^{\mathrm{a}}$ On a 7-day diary at week 12

${ }^{\mathrm{b}}$ Full analysis set for incontinence (placebo, $N=168$; vibegron, $N=192$; tolterodine, $N=128$ )

${ }^{*} P<0.05 ; * * P<0.001$ vs. placebo 


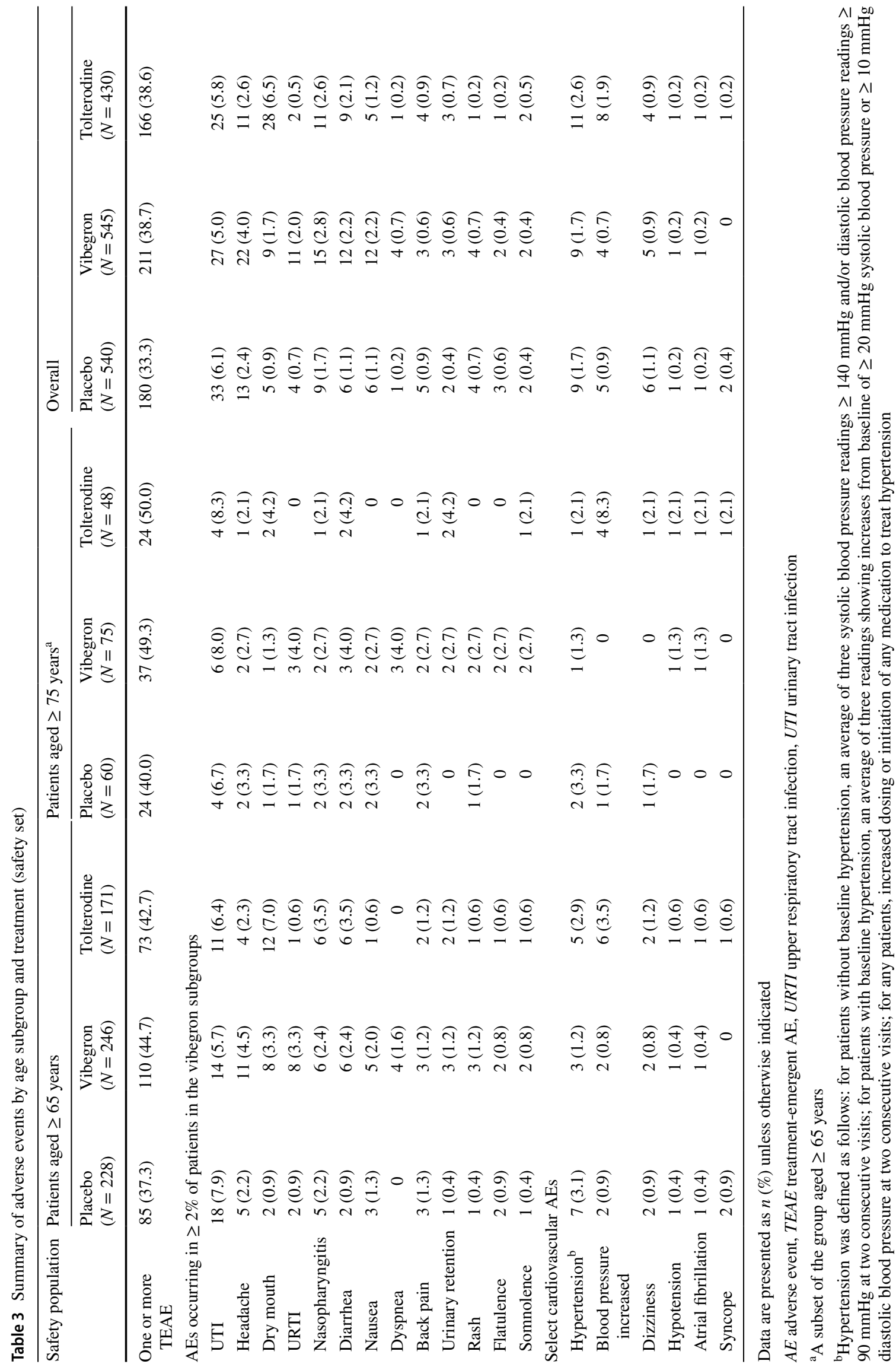


aged $\geq 65$ and $\geq 75$ years in the coprimary endpoints of change in frequency of micturition and UUI episodes and in the key secondary endpoint of urgency episodes. Compared with tolterodine, numerical differences favoring vibegron were seen in older patients for change in the frequency of micturitions and urgency episodes. The efficacy findings in this subpopulation analysis of older age groups are consistent with those demonstrated in the overall EMPOWUR study population [18]. Given that the prevalence of OAB increases with age, the consistent efficacy profile of vibegron in the elderly population is clinically important.

Anticholinergic medications are often prescribed for the treatment of $\mathrm{OAB}$; however, this therapeutic class is associated with AEs such as dry mouth, dry eyes, and constipation, which may be particularly problematic in older patients. Additionally, anticholinergic medications have been associated with cognitive decline and dementia [14, 19] and increased falls in postmenopausal women [20]; in patients with $\mathrm{OAB}$, a higher cumulative anticholinergic burden is associated with higher rates of falls and fractures [21]. Compared with the overall population, patients who received vibegron had generally similar rates of AEs versus placebo for both the subgroups aged $\geq 65$ and $\geq 75$ years. As expected, dry mouth, a common anticholinergic AE, was consistently more common with tolterodine than with vibegron. Rates of cardiovascular-associated AEs were low across all age subgroups of patients receiving vibegron and were similar to those with placebo. The low rates of cardiovascular AEs in this study is an important finding, especially given the older patient population [22]. Among patients who received vibegron, a highly selective $\beta_{3}$-adrenergic receptor agonist, rates of both hypertension and increased BP among adults aged $\geq 65$ years or $\geq 75$ years were similar to or lower than those in patients who received placebo or tolterodine.

Vibegron may provide important safety advantages in older patients with OAB. The potential for DDIs is an important consideration when selecting an OAB treatment. Polypharmacy is common among older patients, and patients with $\mathrm{OAB}$ use more concomitant medications than those without OAB [6]. Polypharmacy has been reported to be more prevalent among patients with OAB aged $\geq 75$ years than those aged $<75$ years [23]. Further, $74 \%$ of patients in long-term care facilities are receiving CYP2D6 substrates [24]. Importantly, vibegron does not inhibit CYP isoenzymes, including CYP2D6 [17], which is an important metabolic pathway for many drugs (including those commonly used in elderly populations such as donepezil, tramadol, venlafaxine) [25].

While sample size calculation was performed for the primary EMPOWUR study, this subpopulation analysis was not powered to detect differences within subgroups and is therefore limited by the small sample size, particularly in the subgroup of patients aged $\geq 75$ years. Efficacy and safety results for vibegron observed in both age subgroups were consistent with those seen in the overall EMPOWUR population.

\section{Conclusions}

The results of this subpopulation analysis of patients aged $\geq 65$ and $\geq 75$ years in the EMPOWUR study align with the results of the overall population showing that once-daily vibegron $75 \mathrm{mg}$ is efficacious across all symptoms of OAB and generally safe and well tolerated for the treatment of $\mathrm{OAB}$. Vibegron represents a beneficial treatment option for patients with $\mathrm{OAB}$ in all age groups studied.

Acknowledgments Medical writing and editorial support was provided by Krystina Neuman, PhD, CMPP, of The Curry Rockefeller Group, LLC (Tarrytown, NY, USA), and was funded by Urovant Sciences (Irvine, CA, USA). This study was funded by Urovant Sciences (Irvine, CA, USA).

\section{Declarations}

Funding This study and medical writing and editorial support for the preparation of this manuscript were funded by Urovant Sciences (Irvine, CA).

Conflicts of interest S. Varano is principal investigator for Clinical Research Consulting and adjunct professor at Sacred Heart University and University of Bridgeport. D. Staskin is an investigator and consultant for Urovant Sciences; a consultant, investigator, and speaker for Astellas Pharma; and a consultant for New Uro B.V. J. Frankel is an investigator for Urovant Sciences, an investigator and speaker for Astellas Pharma and Pfizer Inc., and a speaker for Tolmar Inc. D. Shortino, R. Jankowich, and P.N. Mudd Jr are employees of Urovant Sciences and may be shareholders.

Ethics approval The EMPOWUR study was conducted in compliance with Good Clinical Practice. Institutional review board, research ethics board, or independent ethics committee was obtained before study initiation. All patients provided written informed consent.

Availability of data and materials Request for data from Urovant Sciences (email: medinfo@urovant.com) will be considered from qualified researchers on a case-by-case basis.

Open Access This article is licensed under a Creative Commons Attribution-NonCommercial 4.0 International License, which permits any non-commercial use, sharing, adaptation, distribution and reproduction in any medium or format, as long as you give appropriate credit to the original author(s) and the source, provide a link to the Creative Commons licence, and indicate if changes were made. The images or other third party material in this article are included in the article's Creative Commons licence, unless indicated otherwise in a credit line to the material. If material is not included in the article's Creative Commons licence and your intended use is not permitted by statutory regulation or exceeds the permitted use, you will need to obtain permission directly from the copyright holder. To view a copy of this licence, visit http://creativecommons.org/licenses/by-nc/4.0/. 


\section{References}

1. Stewart WF, Van Rooyen JB, Cundiff GW, et al. Prevalence and burden of overactive bladder in the United States. World J Urol. 2003;20:327-36.

2. Dooley Y, Kenton K, Cao G, et al. Urinary incontinence prevalence: results from the National Health and Nutrition Examination Survey. J Urol. 2008;179:656-61.

3. Coyne KS, Sexton CC, Vats V, et al. National community prevalence of overactive bladder in the United States stratified by sex and age. Urology. 2011;77:1081-7.

4. Coyne KS, Sexton CC, Bell JA, et al. The prevalence of lower urinary tract symptoms (LUTS) and overactive bladder (OAB) by racial/ethnic group and age: results from OAB-POLL. Neurourol Urodyn. 2013;32:230-7.

5. Milsom I, Kaplan SA, Coyne KS, et al. Effect of bothersome overactive bladder symptoms on health-related quality of life, anxiety, depression, and treatment seeking in the United States: results from EpiLUTS. Urology. 2012;80:90-6.

6. Ganz ML, Liu J, Zou KH, et al. Real-world characteristics of elderly patients with overactive bladder in the United States. Curr Med Res Opin. 2016;32:1997-2005.

7. Coyne KS, Payne C, Bhattacharyya SK, et al. The impact of urinary urgency and frequency on health-related quality of life in overactive bladder: results from a national community survey. Value Health. 2004;7:455-63.

8. Liberman JN, Hunt TL, Stewart WF, et al. Health-related quality of life among adults with symptoms of overactive bladder: results from a U.S. community-based survey. Urology. 2001;57:1044-50.

9. Chiaffarino F, Parazzini F, Lavezzari M, et al. Impact of urinary incontinence and overactive bladder on quality of life. Eur Urol. 2003;43:535-8.

10. Kinsey D, Pretorius S, Glover L, et al. The psychological impact of overactive bladder: a systematic review. J Health Psychol. 2016;21:69-81.

11. Gormley EA, Lightner DJ, Burgio KL, et al. Diagnosis and treatment of overactive bladder (non-neurogenic) in adults: AUA/ SUFU guideline: American Urological Assocation. 2019.

12. Lightner DJ, Gomelsky A, Souter L, et al. Diagnosis and treatment of overactive bladder (non-neurogenic) in adults: AUA/SUFU guideline amendment 2019. J Urol. 2019;202:558-63.

13. Maman K, Aballea S, Nazir J, et al. Comparative efficacy and safety of medical treatments for the management of overactive bladder: a systematic literature review and mixed treatment comparison. Eur Urol. 2014;65:755-65.

14. Coupland CAC, Hill T, Dening T, et al. Anticholinergic drug exposure and the risk of dementia: a nested case-control study. JAMA Intern Med. 2019;179:1084-93.
15. American Geriatrics Society Beers Criteria Update Expert Panel. American Geriatrics Society 2019 Updated AGS Beers Criteria ${ }^{\circledR}$ for potentially inappropriate medication use in older adults. J Am Geriatr Soc. 2019;67:674-94.

16. Griebling TL, Campbell NL, Mangel J, et al. Effect of mirabegron on cognitive function in elderly patients with overactive bladder: MoCA results from a phase 4 randomized, placebo-controlled study (PILLAR). BMC Geriatr. 2020;20:109.

17. Edmondson SD, Zhu C, Kar NF, et al. Discovery of vibegron: a potent and selective $B 3$ adrenergic receptor agonist for the treatment of overactive bladder. J Med Chem. 2016;59:609-23.

18. Staskin D, Frankel J, Varano S, et al. International phase III, randomized, double-blind, placebo and active controlled study to evaluate the safety and efficacy of vibegron in patients with symptoms of overactive bladder: EMPOWUR. J Urol. 2020;204:316-23.

19. Weigand AJ, Bondi MW, Thomas KR, et al. Association of anticholinergic medication and $\mathrm{AD}$ biomarkers with incidence of MCI among cognitively normal older adults. Neurology. 2020;95:e2295-e2304.

20. Marcum ZA, Wirtz HS, Pettinger M, et al. Anticholinergic medication use and falls in postmenopausal women: findings from the Women's Health Initiative Cohort study. BMC Geriatr. 2016;16:76.

21. Szabo SM, Gooch K, Schermer C, et al. Association between cumulative anticholinergic burden and falls and fractures in patients with overactive bladder: US-based retrospective cohort study. BMJ Open. 2019;9:e026391.

22. Santulli G, Iaccarino G. Pinpointing beta adrenergic receptor in ageing pathophysiology: victim or executioner? Evidence from crime scenes. Immun Ageing. 2013;10:10.

23. Yoshida M, Nozawa Y, Kato D, et al. Safety and effectiveness of mirabegron in patients with overactive bladder aged $\geq 75$ years: analysis of a Japanese post-marketing study. Low Urin Tract Symptoms. 2019;11:30-8.

24. Yeaw J, Shah D, Kincaid A, et al. Overactive bladder in the United States long-term care setting is associated with significant burden and increased healthcare resource utilization and costs: a retrospective database study. Virtual ISPOR; 2020; May 18-20. https ://www.valueinhealthjournal.com/article/S1098-3015(20)31652 $-1 /$ abstract.

25. Zanger UM, Schwab M. Cytochrome P450 enzymes in drug metabolism: regulation of gene expression, enzyme activities, and impact of genetic variation. Pharmacol Ther. 2013;138:103-41. 